\title{
Reflexiones sobre el proyecto de una biblioteca virtual para la FADU*
}

\author{
Ms. Arq. María Elena Tosello, Arq. María Georgina Bredanini, Arq. Patricia Mines \\ Docentes investigadoras FADU/UNL
}

El presente artículo está basado en el proyecto de investigación y desarrollo CAI+D 2005, UNL: Diseño y Desarrollo de una Biblioteca Virtual para la FADU en curso. Asimismo contiene algunos conceptos incluidos en el artículo «BV Biblioteca Virtual, El Árbol Virtual del Conocimiento» presentado por la Arq. Tosello en SIGraDi 2007 (Tosello, 2007).

En ellos señalamos que el objeto de la investigación es la recopilación, digitalización y catalogación de la producción académica de los miembros de la comunidad educativa de la FADU a los fines de sumarlos a la red de información e intercambio existente; y el diseño y la aplicación de una interfase gráfica novedosa que en un sitio web contenga, difunda y posibilite nuevos modos de aproximación a dicha información.

Actualmente, y después de haber completado varias de las etapas del plan de trabajo propuesto, nos parece importante volcar algunas reflexiones surgidas del desarrollo del proyecto.

\section{Las bibliotecas e internet}

«La cantidad de mensajes en circulación jamás ha sido tan grande, pero disponemos de muy pocos instrumentos para filtrar la información pertinente, para realizar aproximaciones según significaciones y necesidades siempre subjetivas, para localizarnos dentro del flujo de información. Es así que el espacio del conocimiento deja de ser objeto de certeza para convertirse en proyecto.

Según este enfoque, el proyecto arquitectural mayor del siglo XXI será imaginar, construir y acondicionar el espacio interactivo y moviente del ciberespacio [...] quizás entonces será posible... que las técnicas de comunicación sirvan para... navegar por el conocimiento y para pensar de conjunto más que para (solamente) arrastrar masas de informaciones». (Lévy, 2004)

Hasta la consolidación y difusión masiva de Internet las bibliotecas físicas constituían los únicos lugares en donde se accedía a la información bibliográfica, contenida mayoritariamente en soporte papel, y en tanto centros informativos sobre la cultura, su misión como ámbito educativo era hacer accesibles sus recursos a la comu- nidad y mantener actualizado ese espacio dinámico de conocimientos y creatividad como base para la construcción de nuevos saberes.

Hoy existen numerosas bibliotecas que ofrecen sus catálogos, exposiciones y salas de lectura on-line.

La Universidad Nacional del Litoral ha creado una Red de Bibliotecas, con una interfase gráfica elemental, que está constituida por las unidades de información de todas sus facultades e institutos. A través de esta red se puede consultar el catálogo con el listado de los 230.000 números disponibles.

http://www.fcjs.unl.edu.ar/biblioteca/

http://www.fbcb.unl.edu.ar/biblioteca/

http://www.fich.unl.edu.ar/biblioteca/

http://www.fce.unl.edu.ar/biblioteca/

Dentro del Programa de Bibliotecas del Centro de Telemática, la UNL está llevando a cabo varios proyectos: la Biblioteca Central, el Lector Único y una Biblioteca Digital que contendrá las tesis de la Universidad. Este proyecto no incluye el diseño de la interfase gráfica.

La Biblioteca de la Facultad de Arquitectura, Diseño y Urbanismo de la Universidad Nacional del Litoral dispone de numerosos libros y publicaciones periódicas. Hasta hace pocos meses el acceso a esta información tenía lugar únicamente en el edificio de la FADU. La información disponible hoy on-line se reduce a los datos bibliográficos principales del catálogo (nombre, autor, editorial y signatura topográfica), y propone una navegación sencilla y tradicional. Lamentablemente el material intelectual no librario de grado y de posgrado producido por docentes, investigadores y alumnos (tesis, conferencias y trabajos de investigación y extensión) no está disponible porque no ha sido registrado en forma sistemática.

\section{Interdisciplina y especificidad}

«El abordaje de nuevas temáticas que derivan del avance tecnológico..., exige un dominio de instrumentos conceptuales y operacionales múltiples... Esta imparable "colonización interdisciplinar" del ciberespacio estimula nuevas reflexiones sobre la especificidad de lo arquitectónico y del diseño...» (Chiarella, 2004). 


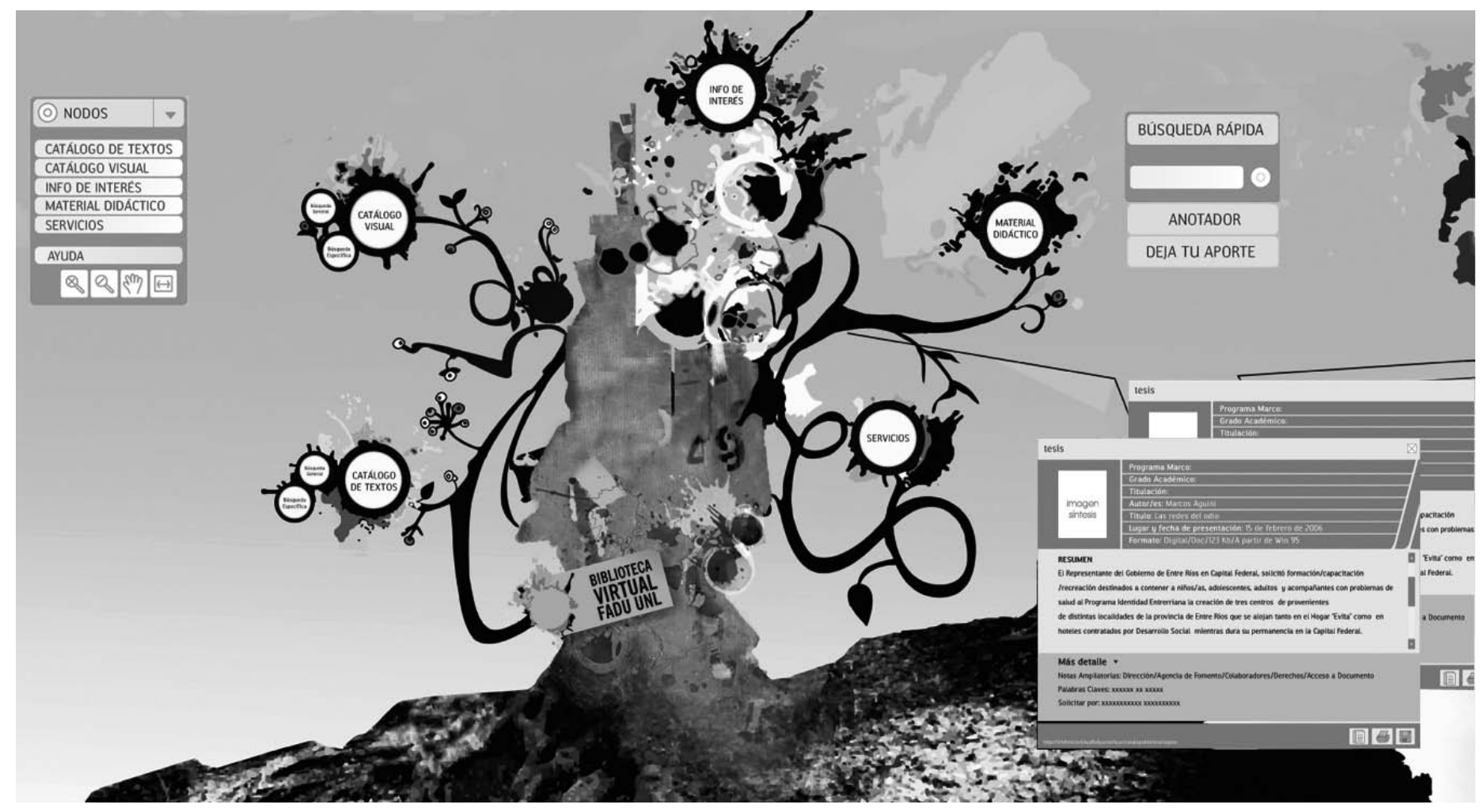

Figura 1. Imagen de las autoras.

* Proyecto de Investigación CAI+D 2005: Diseño y desarrollo de une biblioteca virtual para la FADU. Programa de actividades científicas y tecnológicas (РACT): Medio digital. Diseño, proyectación y cultura virtual. Secretaría de Ciencia y Tecnología, UNL.
El enfoque interdisciplinario es de fundamental importancia para este tipo de proyectos, ya que la convergencia de diversas disciplinas científicas posibilita incorporar elementos significativos en el sentido de la construcción de un ámbito novedoso y adecuado de difusión e intercambio de información. Las Ciencias de la Bibliotecología, la Computación, la Arquitectura y el Diseño, aportan en esta dirección.

El modo de trabajo de colaboración definido en este entorno en donde los participantes consolidan el equipo con un adecuado soporte tecnológico (que permite entre otras cosas el trabajo y la carga de datos a distancia), se apoya en un conjunto de estrategias tendientes a maximizar los resultados y minimizar la pérdida de tiempo e información en beneficio de los objetivos del proyecto.

Pero, más allá de los enunciados debemos señalar que fue justamente en este diálogo interdisciplinario en donde encontramos las principales dificultades del proyecto. La construcción de un lenguaje común entre los distintos enfoques específicos insumió mayor tiempo del esperado y generó importantes corrimientos en las fases de desarrollo específicas. Ejemplo de ello fueron los desfasajes temporales entre las producciones referidas al diseño visual y el diseño de la arquitectura de la información. Para la definición de la especificidad del sitio (biblioteca de la Facultad de Arquitectura, Diseño y Urbanismo) se tomaron en cuenta aspectos relacionados con las teorías de Diseño web centrado en el usuario (Hassan; Martín-Fernández; lazza, 2004), especialmente destacamos el principio de «usabilidad en tanto grado de satisfacción logrado por usuarios específicos en contextos de uso específico».

Para cumplir con este objetivo y adecuar el diseño de su interfase y de los servicios que brinda la biblioteca virtual en función de las demandas de los usuarios, fue primordial identificar el perfil de los usuarios potenciales. Es decir, tanto de aquellas personas que harán uso efectivo y sistemático de los servicios y recursos de la biblioteca, ya que forman parte de la unidad académica de pertenencia; así como de aquellos usuarios que sin pertenecer a la unidad académica, pueden hacer uso de los servicios de la biblioteca virtual a través de la web. El mayor grado de satisfacción y calidad de servicios de información, educación e investigación que brinde la biblioteca virtual, será posible siempre y cuando se conozca el perfil de los usuarios que accederán a esa información.

En este sentido, con el objetivo de obtener datos referidos al perfil de los potenciales usuarios de la Biblioteca Virtual para la FADU, se recabó información estadística acerca de las tendencias de navegación de un grupo de 1.581 estudiantes de esta unidad académica.

Tomando como base las tendencias de los usuarios mencionados, fue posible tomar algunos datos relevantes que 
hacen al perfil técnico de los usuarios y así establecer algunas premisas para el diseño de la interfase gráfica de navegación de la Biblioteca Virtual de la FADU.

\section{Diseño visual / imagen institucional \\ El árbol del conocimiento:}

La pantalla de acceso se construye a partir de la imagen de un árbol en relación a la metáfora de orígen bíblico del «árbol del conocimiento del bien y del mal» 0 «árbol de la sabiduría» (Génesis, 2:17), asumida por nuestra cultura occidental; además, representa a su vez la forma estructural y organizacional del sistema de directorios y archivos informáticos. Convergentemente, Humberto Maturana en su libro El árbol del conocimiento trata una visión alternativa de las raíces biológicas de la inteligencia, proponiendo al conocimiento, no como una representación real del mundo exterior, sino como la continua creación de un mundo a través del proceso mismo de la vida (autopoiesis), una invitación para desprenderse de las certidumbres y adquirir una nueva visión biológica de lo que significa ser humano.

Como es intención de este proyecto consolidar una identidad propia de la FADU, ya que fuera una de las facultades pioneras a nivel nacional en el uso y aplicación de la tecnología digital en diversas áreas: diseño, docencia, patrimonio arquitectónico, teoría, información y comunicación, los colores que se utilizan son los institucionales de la FADU UNL.

\section{Carácteristicas del espacio:}

La pantalla de acceso está siempre presente, así el usuario va ingresando a los diferentes nodos sin perder de vista su ubicación en el contexto general, en el espacio contenedor. El ingreso a la información se realiza a partir de un acercamiento a los nodos principales de la pantaIla de acceso. Los conceptos sobre los cuales se estructuró la navegación son:

- zoom;

- fragmentación;

- profundidad.

La idea es generar a partir de estos conceptos un espacio potencial que contenga sub-espacios. El usuario puede realizar la búsqueda y obtener los resultados en un mismo espacio, como si estuviera trabajando sobre su escritorio, construido por elementos flotantes superpuestos (ventanas), siendo el usuario el que jerarquiza la información.

\section{Programación / interfase gráfica novedosa (diseño conceptual)}

Los mecanismos más usuales utilizados en Internet para acceder a la información están basados en el lenguaje escrito, ya que tanto las búsquedas como los resultados se realizan a través de palabras y la forma de representación de la información es de carácter bidimensional como su nombre lo indica: páginas, sin considerar que este ambiente virtual aún no se encuentra definido ni categorizado en sus posibles dimensiones. A partir del avance de las TIC, Tecnologías de la Información y la Comunicación, es posible representar la información incorporando otras dimensiones espacio-temporales y ofrecer otros canales de acceso como imágenes, sonidos y videos. El medio digital presenta una gran potencialidad para ampliar las estrategias de representación y comunicación de la información, logrando como resultado un acceso más fluido y eficaz a la misma, y facilitando la actividad cognitiva ya que se dispone de una mayor variedad de estímulos.

\section{Interfase:}

Proponemos una interfase gráfica innovadora con un sistema de canales alternativos de acceso a la información, utilizando códigos de representación textuales y visuales. La búsqueda continúa siendo a partir de palabras, pero tiene lugar en un entorno visualmente más rico para lograr una comunicación más efectiva (Figura 1). Los resultados se presentan a través de textos, imágenes o simulaciones 3D, dependiendo del catálogo consultado.

El diseño de la interfase se basa en la metáfora del escritorio, en la posibilidad de tener todos los libros sobre la mesa de trabajo (múltiples ventanas), incluyendo un anotador o bloc de hojas para hacer el resumen (Chen; Maver, 1996). La navegación simulará una experiencia espacial, exploratoria y lúdica.

«La simulación como alternativa a la experiencia física..., aporta nuevos contenidos a nuestra experiencia 
del mundo, construyendo nuevos paradigmas culturales... La interconexión ilimitada entre hombre e información posibilita la construcción de nuevos saberes...» (Chiarella, 2004).

El diseño hipermedial requiere de un guión o narrativa, que considere las posibilidades de recorrido y los acontecimientos o eventos que tendrán lugar a cada paso. Para que la navegación sea más ágil, estudiamos detalladamente la estructura de enlaces o vínculos, para minimizar la cantidad de pantallas necesarias y por ende, el tiempo.

\section{Programación:}

La programación se estructura de manera de lograr una gestión de búsqueda eficiente para obtener ágilmente los resultados y optimizar la performance.

El proyecto comprende el uso de distintas tecnologías. Se optó por software Open Source para el Back End y Web Server, y Macromedia Flash como interfase gráfica. El servidor web utilizado es Apache, el motor de bases de datos es MySQL y el lenguaje de programación es PHP.

Se utiliza como antecedente la ficha modelo diseñada por el Coordinador del Programa de Bibliotecas y Director del Centro de Telemática de la UNL, Dr. José Luis del Barco para la catalogación de las tesis de doctorado de la Universidad. Esta ficha contiene etiquetas de elementos de metadatos Dublin Core previendo la interacción con otras bibliotecas.

A través de la interfase Flash, el sistema realiza una búsqueda en la base de datos y devuelve los resultados según los criterios utilizados, para luego mostrarlos de manera gráfica. Aprovechando las capacidades de javascript, las fichas de cada libro (resultado de la búsqueda) se pueden mostrar con distintos niveles de profundidad. Diseño de contenidos y modo de acceso a la información La organización y catalogación de los contenidos se realizó en función del análisis minucioso de los antecedentes on-line. El modo de acceso a la información será a través de nodos (Rodríguez Barros, 2004) que sintetizaran la selección de los contenidos para cada uno y la elección de los nombres de modo tal que sean interpretados claramente (legibilidad). Para poder ver el contenido de los nodos el usuario se acercará a ellos mediante sucesivos zooms. Para los usuarios interesados en interactuar
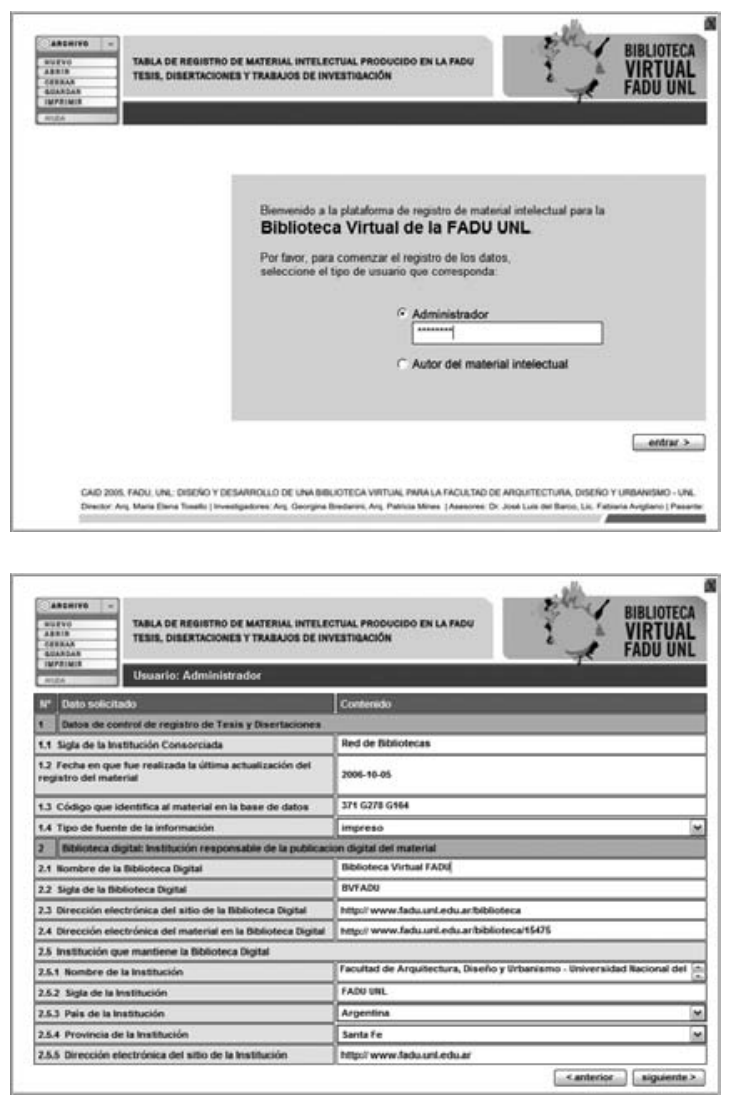

Figuras 2 y 3.

con la página del modo convencional, estará disponible la opción de acceder mediante el Menú 1 , que contendrá las mismas opciones que los nodos, pero ordenadas verticalmente en una lista desplegable.

Los nodos son:

- Catálogo de textos: libros, revistas, tesis, proyectos de investigación y extensión, artículos, conferencias y documentos oficiales.

- Catálogo visual: imágenes, multimedia, planimetría, videos, modelos 3D e información catastral.

- Material didáctico: grado y posgrado, Arquitectura y Diseño (divididos según los años y cada año en las materias correspondientes al mismo). Contendrán: programas, apuntes, clases y trabajos prácticos. 
- Servicios: agenda, cursos, novedades, link a otras bibliotecas, foros temáticos, blogs.

- Información general: mapa del sitio, antecedentes, responsables, horarios, ubicación y reglamento de la biblioteca (condiciones de uso).

Los links del Menú 2 poseen otro tipo de información que la contenida en los nodos. Ésta permite al usuario tener algunas ventajas para la navegación y la carga de datos: registración, aportes y anotador.

\section{Recopilación del material intelectual} producido en la FADU

Uno de los propósitos principales del proyecto fue la recopilación, digitalización y registro del material intelectual producido por los integrantes de la comunidad de la FADU. La serie de proyectos llevados a cabo con anterioridad generaron bases de datos importantes pero dispersas que no dialogan entre sí.

En este sentido una de las actividades fundamentales fue el desarrollo de las herramientas necesarias para sistematizar el registro a partir del modelo de metadatos Dublín Core ya citado y los modelos de fichas catalográficas de tesis, congresos, conferencias y jornadas en uso en la Biblioteca Centralizada de la FADU, FHyC y ISM suministrados por la Lic. Fabiana Avigliano.

Sobre esta base se realizaron los ajustes pertinentes al tipo de material a registrar, se diseñaron planillas de registro, formularios para la autorización de publicación electrónica, instructivos y se desarrollo un sistema informático de carga de datos de tesis y proyectos de investigación y extensión. Este último fundamental a los fines de asegurar la exactitud de la información ya que es el mismo autor del trabajo el que realiza el registro.

Este sistema informático de registro es una aplicación visual que puede ser utilizada tanto por los autores del material intelectual como por los administradores de la base de datos de la Biblioteca Virtual para el registro de la información.

El desarrollo del mencionado sistema, se realizó a través un software que facilita la programación utilizando un lenguaje de autor para el diseño de los formularios con los que interactúa el usuario, la asignación de propiedades para las formas y controles, y la asignación de código y variables para los controles, y el comportamiento que van a tener éstos ante las distintas acciones del usuario. La aplicación visual diseñada guía paso a paso al usuario, ya sea el administrador o el autor del material, en la carga de los datos. Finalizada la misma, se incorpora el registro del material a la base de datos, y se genera la versión imprimible del formulario y la autorización para la publicación del material, para que el autor imprima y entregue dicha autorización firmada para ser archivada en la Biblioteca.

\section{El desafío de encontrar nuevos modos}

Actualmente y a partir de las reflexiones que venimos desarrollando para el Curso de actualización y perfeccionamiento docente La enseñanza del proyecto en entornos interactivos de aprendizaje, FADU, UNL, estamos trabajando en la posibilidad de incorporar una nueva forma de búsqueda en el catálogo visual.

De esta manera el catálogo visual que utiliza el mismo 
sistema de catalogación de archivos de texto, sumaría a la búsqueda tradicional la posibilidad de realizar una búsqueda exploratoria o experimental a través de otros parámetros, no verbales.

Se trataría de referencias que con un modo icónico representen conceptos mediante una imagen o un esquema.

Una unidad de diseño, un producto industrial o una obra de arquitectura son el resultado de un proceso de ideación y materialización en el que intervienen elementos primarios de la forma, relaciones entre ellos, principios de organización, materiales, etc. (Tosello; Mines, 1998) Estamos trabajando en la elaboración de ese repertorio de íconos que incluirá entre otros elementos de búsqueda:

- Punto, línea, plano, volumen (en tanto elementos primarios).

- Forma, medida, color, textura (en tanto cualidades de los elementos primarios).

- Dirección, posición, espacio, gravedad (propiedades de los elementos).

- Distanciamiento, toque, superposición, penetración (interpenetración, encadenamiento, entrelazamiento), unión, sustracción (interrelación de formas).

- Eje, simetría, jerarquía, ritmo/repetición, pauta, transformación (principios ordenadores), (Wong, 1979).

Desde esta perspectiva La Biblioteca Virtual de la FADU podrá constituir un espacio donde encontrar material de consulta para alumnos, docentes, investigadores y demás actores dedicados a la Arquitectura y al Diseño por un lado, pero (y fundamentalmente) ofrecerá una oportunidad para imaginar y construir nuevas producciones que puedan ocurrir a partir de esta propuesta.

\section{Referencias}

Chiarella, M. (2004): Programa de actividades científicas y tecnológicas: medio digital. Diseño, proyectación y cultura virtual. Universidad Nacional del Litoral.

Hassan, Y; Martín-Fernández, F; Iazza, G. (2004): «Diseño web centrado en el usuario: usabilidad y arquitectura de la información». hipertext.net, $\mathrm{N}^{\circ} 2$, http://hipertext.net

Lévy, P. (2004): «Inteligencia colectiva por una antropología del ciberespacio». Washington DC, marzo 2004, http://inteligenciacolectiva.bvsalud.org

López Pérez, B. (2006): «Patrón e imagen: inmersión en los sistemas multimedia». Gaceta Triángulo, 12. p. 11

Rodríguez Barros, D. (2004): Hipermedios y dimensiones de análisis en hipermedios y modelos virtuales de fragmentos urbanos. Universidad Nacional de Mar del Plata, Buenos Aires, pp. 49-64.

SIGradi (2007): «La comunicación en la sociedad visual». http://www.sigradimexico.org/tema.htm

Tosello, M. (2007): «BV Biblioteca Virtual. El árbol virtual del conocimiento». SIgradi 2007, 11th Iberoamerican Congress of Digital Graphics. México DF, pp. 24-29.

Tosello, M; Mines, P. (1998): Apuntes de cátedra, Curso de ingreso 1998, Facultad de Arquitectura, Diseño y Urbanismo, unL.

Wong, W. (1979): Fundamentos del diseño bi y tri-dimensional. GG Diseño, Ed. Gilli, Barcelona. pp. 9-12 